\title{
The Praxis OF Grassroots DiPloMACY FOR SOCIAL ENTREPRENEURSHIP
}

\author{
Andrew Hinton \\ Penn State University \\ University Park, PA 16802 \\ ahinton129@gmail.com
}

\author{
Kate Ortbal \\ Penn State University \\ University Park, PA 16802 \\ kate.ortbal@gmail.com
}

\author{
Khanjan Mehta \\ Penn State University \\ University Park, PA 16802 \\ khanjan@engr.psu.edu
}

\begin{abstract}
Social entrepreneurs design and implement innovative, sustainable, and scalable solutions to pressing social challenges across the world. While the success of their ventures is impacted by numerous factors, their long-term viability and endurance depends on the relationships built with diverse stakeholders. The praxis of grassroots diplomacy facilitates the development of harmonious and effective relationships that catalyze social change. This art and science of pro-active conflict avoidance and resolution helps navigate multifaceted social dynamics and develop successful entrepreneurial alliances and ecosystems. With the help of several examples and mini case-studies, this article articulates the meaning and importance of grassroots diplomacy. A conceptual framework based on six core competencies of proactive scenario planning, empathy, trust-based relationship building, equitable collaboration, conflict resolution, and ethical reflection is presented. Finally, a practical methodology that animates these core competences into a structured process that strengthens partnerships and ventures is presented. These concepts, competencies and methodologies are built upon the central tenets of systems thinking and self-determination that leads to systemic self-determined improvement of lives and livelihoods.
\end{abstract}

Index Terms - international development, social entrepreneurship, entrepreneurial ecosystem, grassroots diplomacy, conflict resolution

\section{INTRODUCTION: THE IMPORTANCE OF GRASSROOTS DIPLOMACY}

Academic and professional programs that address global development challenges through the design and commercialization of appropriate technologies are becoming increasingly popular ${ }^{1}$. Academic programs commonly utilize the pedagogy of service learning to create value for partnering communities. ${ }^{2,3,4}$ Similar trends are seen amongst professional organizations; NGOs like Engineers Without Borders and governmental programs like the Peace Corps provide opportunities for professionals to engage in global development challenges. Despite the growing popularity of these programs, their impact can be limited if their focus is on relatively lowimpact, small-scale service activities. The addition of a rigorous entrepreneurial approach has the potential to radically transform and intensify these programs. Entrepreneurship-based programs can provide an environment that nurtures social enterprises that create large-scale impact. 
Programs, academic or otherwise, that embrace an entrepreneurship-based approach can enable individuals to design and launch ventures that are both sustainable and scalable. This paradigmatic shift towards market-centric approaches has been validated by the emergence of successful social enterprises across the energy, agriculture, and healthcare sectors.

Aspiring social entrepreneurs see the importance of integrating design, business planning, and implementation strategy to get their ventures off the ground. ${ }^{5}$ Systems thinking and a transdisciplinary approach become the key to designing innovative and practical solutions to complex problems, especially in resource-constrained environments like those across the developing world. ${ }^{6}$ In addition to the contextual complexities entrepreneurs face, they must often work with a large network of partners that can include communities, industry partners, community-based organizations, non-governmental organizations, faith-based organizations, governmental agencies and UN agencies. ${ }^{7}$ Throughout their entrepreneurial journeys, especially in interacting with the stakeholders in these networks, social entrepreneurs may face a series of microconflicts: tensions, disagreements, intra-personal conflicts, and unique challenges that affect the relationships formed between social entrepreneurs and their stakeholder networks.

Micro-conflicts emerge throughout a venture's lifecycle and can be attributed to issues of (1) ownership and agency, (2) motivations and expectations, (3) position and power, and (4) tension and disagreement. For example, social entrepreneurs may be asked for grease payments or experience conflicts within their teams. Mismanaging these micro-conflicts can stress the venture's structure and wellness and can ultimately lead to its failure. However, when managed successfully, these networks can provide the capital and resources necessary to sustain the venture and create large-scale impact. Social entrepreneurs and the programs that support them must develop a deep understanding of the venture's unique context, stakeholders, and potential micro-conflicts. They must use that information to facilitate collaboration and negotiations as well as to build a culture where self-determination is the norm. An enabling and affirming environment of this sort enables entrepreneurs to mobilize resources across multiple networks.

Social entrepreneurs can build stronger collaborations and efficient operations with the praxis of grassroots diplomacy: a set of delicate and deliberate techniques for working harmoniously and effectively with diverse entities to catalyze social change. ${ }^{8}$ This article discusses the importance of grassroots diplomacy and the four kinds of tensions and microconflicts it can help overcome. A framework for grassroots diplomacy with six core competencies is presented: (1) proactive scenario planning, (2) empathy, (3) trust-based relationship building, (4) equitable collaboration, (5) conflict resolution, and (6) ethical reflection. Finally, a structured methodology to resolve misunderstandings and disputes through grassroots diplomacy and conflict resolution techniques is described. Faculty, students, and practitioners engaged in the development of social enterprises in developing countries will find this article particularly relevant. The genesis of this work is an academic program focused on social entrepreneurship; so the word "entrepreneur" is interchangeable with the word "student". The concepts, frameworks and methodologies presented herein are designed with field practitioners in mind.

\section{BUILding ECOSYSTEMS BASEd ON SELF-DETERMINATION AND SYSTEMS THINKING}

An entrepreneurial ecosystem is made up of a venture's physical environment and the relationships nurtured by entrepreneurial alliances that create a venture's context. ${ }^{9}$ Social entrepreneurs need to consciously build successful ecosystems so that they have the proper 
infrastructure and human capital to design, sustain, and scale operations. Without this, the social and economic benefits for a given venture will be limited. For these ecosystems to fulfill their full potential over time, entrepreneurs need to build alliances that are based on selfdetermination. While entrepreneurs plan strategically to fulfill all of the operational aspects of the venture and shape the physical landscape, they must use tremendous care to build harmonious and organic relationships. To form an entrepreneurial alliance that is capable of maximizing the potential of the venture, entrepreneurs need to be highly collaborative and effective at bringing together diverse parties and ensuring commitment. As shown in Figure 1, potential entrepreneurial alliances include, but are not limited to: innovators, governments, community-based organizations, customers, and employed agents.

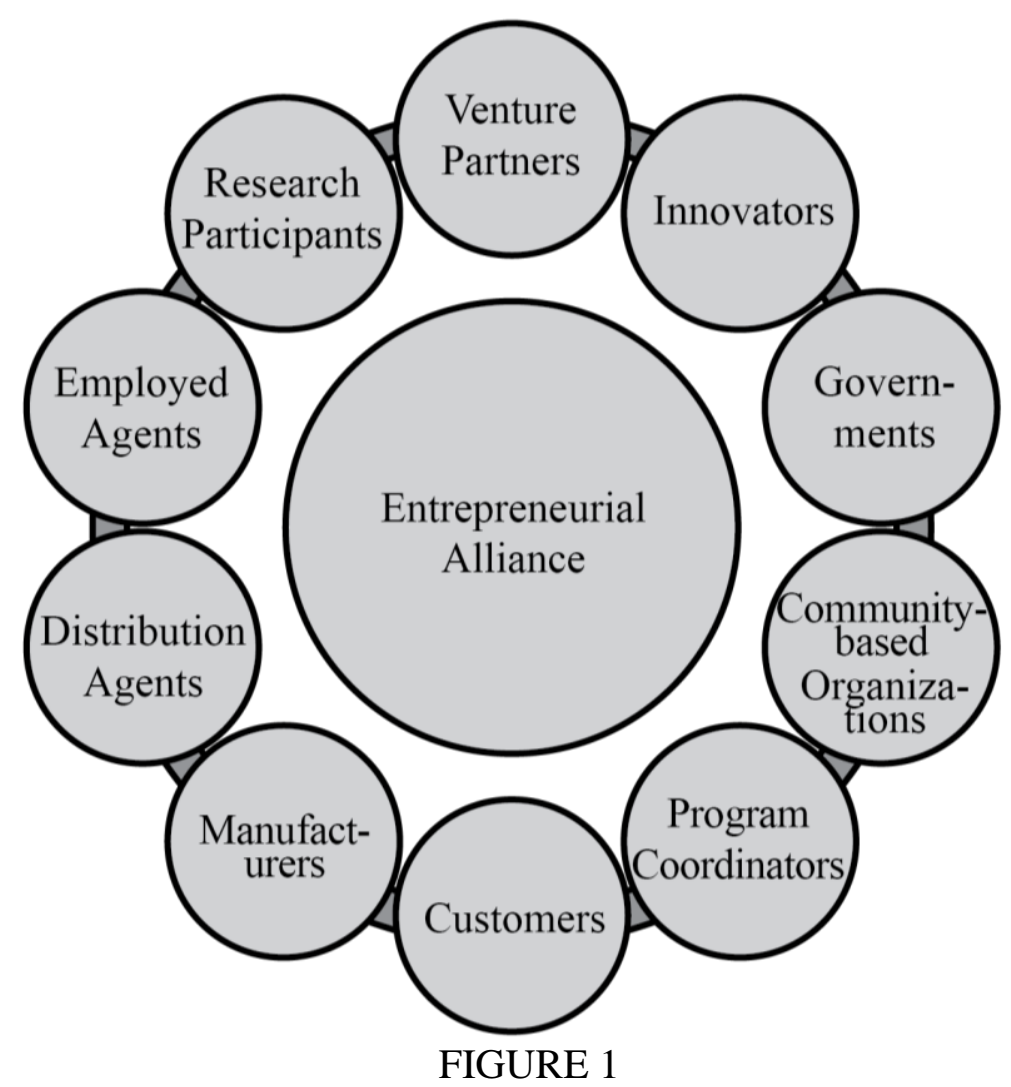

ENTREPRENEURIAL ALLIANCES

An entrepreneur's ability to balance the needs of different parties and motivate them towards a common goal is essential to building a successful entrepreneurial alliance. Generally, diverse stakeholders are motivated by different short-term and long-term benefits and have their own philosophy of why and how they want to engage. For example, social businesses often operate their for-profit and social mission arms independently of one another. ${ }^{10}$ This leaves each social project manager responsible for balancing the wants and needs of both sides and reconciling internal disagreements. A similar situation arises when entrepreneurs work with multiple partners to accomplish a singular goal. Each entity possesses competing expectations and entrepreneurs can easily become entangled in a web of superfluous conflicts. Further, uncovering the true motivations of stakeholders can prove an arduous endeavor. Some individuals will appear to 
have a vested interest in an aspect (say social benefit) but actually desire only financial gain. Entrepreneurs must learn to anticipate such challenges and make strategic decisions that satisfy partners and advance the venture forward. As entrepreneurs seek to uncover stakeholders' interests, they must be aware of their own influence in a situation and remain neutral so that stakeholders can act honestly and with self-determination.

Grassroots diplomacy is a process that social entrepreneurs utilize to build harmony among self-determined alliances. Self-determination is defined as an individuals' ability to pursue goals that are personally meaningful to them. ${ }^{11}$ The notion is that development should lead to freedom $^{12}$ and that indigenous communities will thrive if they find themselves in an environment in which they can effectively improve their lives. ${ }^{13}$ When stakeholders fail to be autonomous, their actions do not reflect self-directed principles; they may be indoctrinated or controlled by other people. ${ }^{14}$ Social entrepreneurs must actively avoid indoctrination or false promises and seek to build stakeholders' capacity for self-determination by promoting freedom for autonomous action and instilling a sense of agency. An agent is an active decision-maker whose decisions achieve an outcome that can be judged based upon self-directed criteria. Empowered community members act freely based on the specific things that they value and become agents of their own economic development. ${ }^{15}$ According to many development scholars, individuals inherently seek their optimal development, but this kind of development is only attainable if individuals are supported by a nurturing environment that makes them feel competent, autonomous and related. ${ }^{16}$ The practice of grassroots diplomacy facilitates the development of such environments that further catalyze equitable entrepreneurial alliances.

As entrepreneurs build ecosystems to employ this philosophy of engagement, they must also utilize systems thinking. A problem solving approach that takes the overall system into account rather than the piecemeal parts, systems thinking involves viewing and understanding how each decision made and action taken affects the venture as a whole. The essential functions of entrepreneurship encompass market research, product design, product development, marketing, commercialization, and business management. ${ }^{17}$ In order to complete these tasks and scale their impact, social entrepreneurs must form partnerships with expanding networks. An alliance is a collaborative relationship built with an individual agent that supports one of these essential functions. Entrepreneurial alliances evolve as the venture adapts and evolves. Each stakeholder is affected by the overall success (or failure) of a venture. They are interdependent, which is why entrepreneurs need to be mindful of their ability to make decisions in accordance with their own beliefs and the advancement of the venture. Ideal relationships involve those in which individuals achieve their own objectives simultaneously as the venture achieves its objectives. ${ }^{18}$ The praxis of grassroots diplomacy focuses on building harmony to reinforce this interdependence. $^{6}$

In order to form and sustain entrepreneurial ecosystems, social entrepreneurs identify unfulfilled needs and build partnerships to fill those needs with specific resources, research studies, or collaborative agreements. The complexities inherent in relationship building with diverse stakeholders, however, can cause scenarios that can affect how individuals take ownership of, and collaborate within, the entrepreneurial ecosystem. Social entrepreneurs, ventures, and stakeholders alike are affected negatively when strong disagreements occur or when communal discord inhibits progress and effective operations. These problematic situations can be referred to as micro-conflicts, and their mitigation is essential to achieving long-term objectives. Grassroots diplomacy plays out as a way of approaching decision-making so that the outcome of an action is advantageous for the venture and relationships. It is both proactive and 
reactive to common problems, known as micro-conflicts, which are explained in greater detail in the next section.

\section{KindS OF Micro-CONFLICTS ENCOUNTERED BY ENTREPRENEURS}

Micro-conflicts are interpersonal issues, challenges, problems, or escalated disagreements involving an entrepreneur's partnerships and operations. Entrepreneurs need to quickly resolve problems that can affect relationships and compromise the entrepreneurial ecosystem. There is tremendous diversity of norms, resource constraints, customs, and traditions in regions of the world where social entrepreneurs work. The micro-conflicts explained in this section reflect common issues that entrepreneurs might confront. They serve as case studies and promote understanding of the conceptual framework of grassroots diplomacy. Each description and subsequent example demonstrates a common issue, problem, challenge, or conflict - the latter being an escalation of a tense disagreement. These factors are amplified by the delicate dynamics and tensions that exist when an individual engages in an ecosystem with which they have less prior experience. The praxis of grassroots diplomacy provides a way of relating with others and making decisions that sustain alliances despite the following micro-conflicts.

\section{Ownership \& Agency}

Entrepreneurs displaying leadership, vision, and management skills are most successful, yet few studies address the role of an individual's ego. ${ }^{19}$ Individualism pervades entrepreneurship and owners of enterprises that view the world from an introspective lens tend to make moral judgments that satisfy their personal welfare and vision. ${ }^{20}$ In addition, overly optimistic entrepreneurs that emphasize product over process fail to discover the value inherent in collaboration and teamwork. ${ }^{21}$ Entrepreneurs need to acknowledge their ego, and the role it plays in building alliances. Involving stakeholders is necessary to commercialize products and services that are truly appropriate and viable. ${ }^{22}$ For example, stakeholders that have the freedom to choose how resources are collected and how investments are made can allocate resources according to their self-direction and achieve sustainable ventures for a longer period of time. ${ }^{23}$ Participating in entrepreneurial processes makes stakeholders more integrated in their own development. However, the delegation of roles within complex systems presents a challenge. Issues often arise with ownership models and agency of community collaborators.

For instance, take the case of a social enterprise that sells affordable greenhouses to subsistence farmers. The entrepreneur is enthusiastic to do business in a developing community, and explains his vision for the design to members of the community. He then enlists their help in constructing various greenhouses and is impressed by their knowledge and abilities. When the greenhouse venture expands, those in the initial construction process want to share ownership in the business's development. As the venture's success grows, more community stakeholders wish to join with the innovator. Community members demonstrate their willingness to be agents that support the innovator's vision, yet the innovator does not have the assets to employ each of them as a construction agent. Consequently, the innovator has a conflict associated with ownership of the social venture on his hands. 


\section{Motivations \& Expectations}

Personal and professional motives influence individuals' behavior and decisions. The challenge is balancing these motivations with the venture objectives so both can succeed simultaneously. Prioritizing personal relationships and a sense of camaraderie over ethical principles and professional responsibilities produces inefficient working relationships. ${ }^{24}$ Actions and expectations set primarily to please a partner or stakeholder can also cause problems, especially actions and expectations that influence a technical component of the venture. Entrepreneurs may approve decisions that advance a flawed idea, design, implementation, or business model because they hope it will be successful. Further, promises made beyond the realistic capabilities of the venture lead to tense situations when the venture does not meet the expectations laid out in prior conversations.

As in the previous example, an affordable greenhouse project leader collaborates with community members - this time a farmer and a businesswoman. They appeared to be optimal alliances to take care of several things while the innovator focused on researching the best methods to design the greenhouse. The farmer's role was to take care of the greenhouse prototypes and cultivate the crops. The businesswoman had responsibilities of marketing the greenhouse externally. When the innovator returns from his research practice, the prototypes are worn and tattered. The farmer had abandoned his efforts. The businesswoman, on the other hand, had made many potential partnerships. The innovator discovers that the farmer is only interested in building a friendship with the innovator and not invested in improving the productivity of the prototype. The farmer was unmotivated by the venture and had low expectations for the project to provide him a better life. The businesswoman set reasonable expectations and built a strong network throughout external communities due to her motivation to advance her own career as well as the venture. However, since she had nothing substantive to validate the product, the venture stagnated until the innovator's return. Personal and professional motivations play a role in the decisions people make. By understanding these motives as well as holding realistic expectations about the future, entrepreneurs build ventures more appropriate for their working environments.

\section{Position \& Power}

Many factors affect the way in which individuals are perceived, including gender, social class, discipline, age, political affiliation, religion, and nationality. ${ }^{25}$ Social entrepreneurs need to be aware of, and properly negotiate, instances when interpersonal factors are influenced by positional status. ${ }^{26}$ These dynamics are a function of unavoidable perceptions, which can be problematic for social entrepreneurs as they navigate radically different cultural settings. For example, racism and sexism may influence relationships between researchers and research participants in addition to partnerships between business associates. ${ }^{27}$ Further, opportunistic individuals may perceive those from an outside group to be exploitable. Community members may overcharge for basic commodities or expect financial incentives for minor assistance due to their perception of the wealth of the outsiders. Entrepreneurs need to reduce instances when power dynamics or positional status affects an individual's freedom to choose how to act.

For example, an innovator conducting a greenhouse market survey experiences a situation in which interview subjects expect compensation for their time despite the fact that the innovator explicitly mentioned there would be no payment. The participants responded by telling the innovator that as a man from a foreign country, he must be rich and could afford to give them a few coins for their trouble. As the research project continued, the innovator notices another 
detrimental situation. The wealthier citizens of the town approach the innovator asking for interviews. Meanwhile, fewer of the poorest villagers participate. The innovator asks a member of the wealthier demographic and learns that the poorest have nothing to contribute. He asks a member of the less wealthy demographic and discovers that since there is no payment, there is no reason to participate. They go on to say they do not feel comfortable due to social stigmas. Perceived position and wealth, in this example, impacts how the innovator is treated by community members and how the dynamics of power affect research conducted for the advancement of the venture.

\section{Tension \& Disagreement}

Disagreement among team members is unavoidable but incited conflict between an entrepreneur and any stakeholder will negatively affect the venture. Disagreements - defined as differences of opinions based on a person's upbringing, morals, interests, or expectations — can be tolerated as long as they are not intensified too much. ${ }^{28}$ When a member of the community feels discouraged or dissatisfied with the venture or entrepreneur, he or she may be uncooperative or contribute less meaningfully. Personality clashes and aggressive behavior also lead to community tensions, affecting relationships among partners and stakeholders and often result in individual conflicts. ${ }^{24}$ While social entrepreneurs welcome differing opinions in order to spark innovation, they must be wary of the impact of disagreement. When disagreement occurs, entrepreneurs need to handle disagreement constructively and resolve particularly strong disagreements before they get worse.

For example, for the greenhouse venture, an innovator works with translators to instruct local community members interested in becoming greenhouse construction workers. Originally, the team chooses ten individuals from the community to serve as translators, compensating those who worked with a small stipend. Over time, the team worked well with three translators and preferred to keep them on for full-time service. The other translators became upset that they were no longer being treated fairly and began to spread rumors about the team. The translators that remained for full-time service also grew weary of the impact of their relationship with the innovator on their status within the community. In this example, tensions caused unnecessary hardship and upset the delicate community dynamics of the entrepreneurial alliances.

\section{THE PRAXIS OF GRASSROOTS DIPLOMACY}

Various micro-conflicts inhibit the sustainability of alliance-building processes and so it is important to learn how to practice grassroots diplomacy. Optimal alliance-building processes involve entrepreneurs and stakeholders working together toward their unique personal and professional interests as well as venture-specific goals and objectives. Within the systems where entrepreneurs operate, individuals will have to balance a multitude of needs, desires, motivations and expectations. In addition, tense situations may harbor tense work relationships. Figure 2 depicts the Grassroots Diplomacy Framework, showing six core competencies that enhance entrepreneurial ecosystems by addressing these interpersonal factors. 


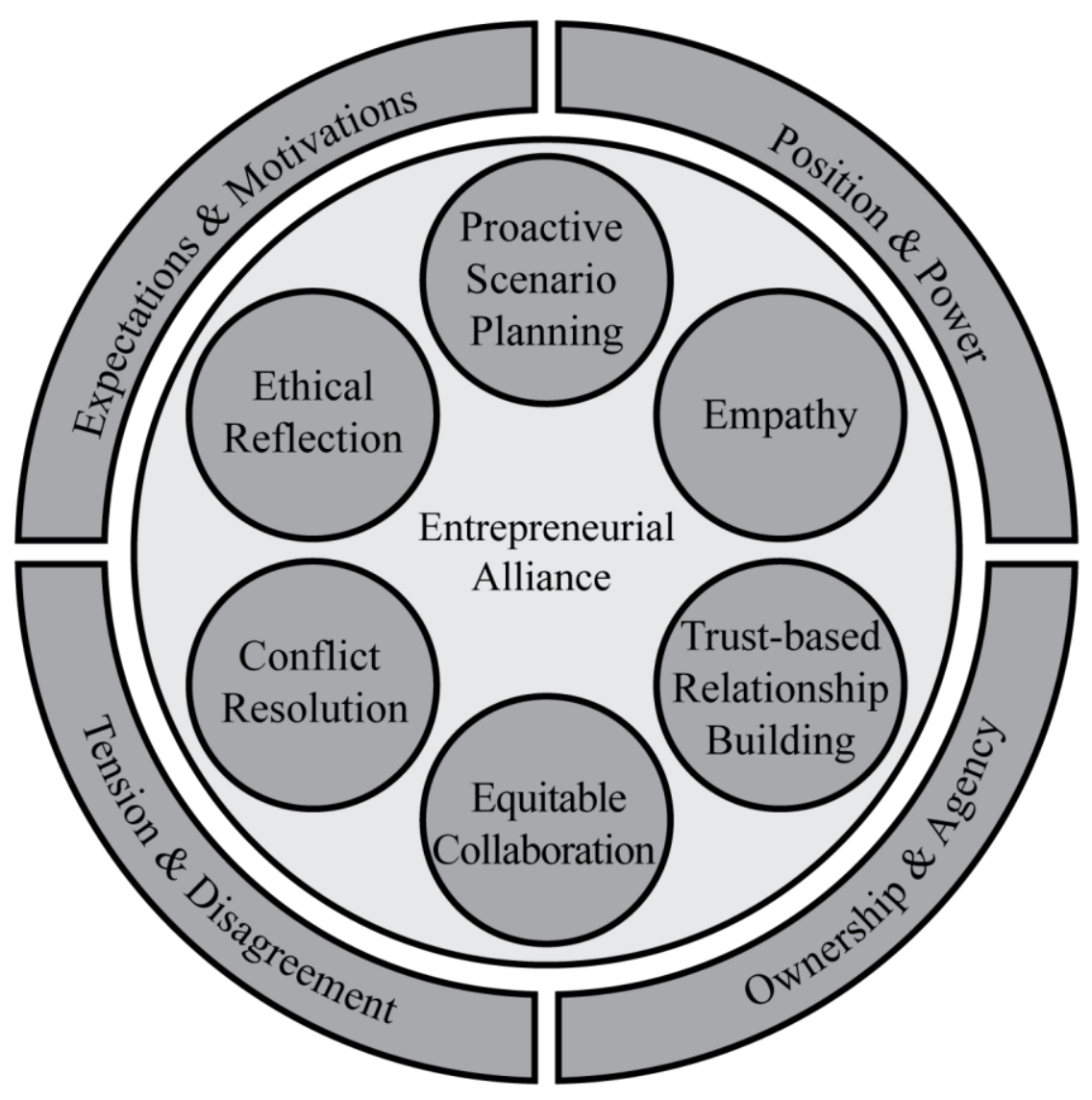

FIGURE 2

GRASSROOTS DIPLOMACY FRAMEWORK

The praxis of grassroots diplomacy involves creating and sustaining entrepreneurial alliances in a way that mitigates the consequences of various kinds of micro-conflicts. Poor working relationships diminish the venture, so entrepreneurs need to learn skills through habitual practice and individual reflection. ${ }^{29}$ Practicing the six core competences and reflecting on the acquisition of these competencies is meant to give entrepreneurs what they need to prevent risks that threaten the venture. Each piece of the framework serves as learning objectives to facilitate a more nurturing philosophy of engaging diverse entities. In combination, these competencies encourage positive and sustainable relationships among alliances.

\section{Proactive Scenario Planning}

Proactivity entails the taking of an action prior to the moment when the action is demanded. When entrepreneurs navigate complex ownership dynamics and positional statuses, they inevitably face situations that cause perplexity. ${ }^{24}$ Strategic observation and reflection transforms overwhelming feelings of perplexity into opportunities. ${ }^{30}$ Scenario planning refers to entrepreneurs using their knowledge base to systematically consider possible ways to engage the community. Thus, proactive scenario planning is a context-driven imagination of possible futures presented as narratives. ${ }^{31}$ Entrepreneurs that practice scenario-planning exercises learn how to 
anticipate challenges and plan ahead. ${ }^{32}$ They notice certain perceptions manifested about the future and how decisions and uncertainties are managed. ${ }^{33}$

Effective scenario-planners create scenarios based on collected information and assess the appropriateness of the possible solutions they make up. ${ }^{34}$ For example, when delegating roles and positions of authority, entrepreneurs need to be aware of the political makeup of village communities and other cultural aspects of power dynamics. Many times, a tribal leader will have symbolic power; meanwhile, government officials are in charge of most administrative, legal, and economic functions of the community. Scenario planning to overcome possible microconflicts between leading figures may reduce the potential for one's purpose being misunderstood or raising community tensions unnecessarily. Furthermore, planning for scenarios relating to the prevalence of opportunism, sexism, ageism, and racism can be especially helpful for entrepreneurs. A proactive entrepreneur may draft and adapt ownership models and organizational charts to determine exactly where agents have a role. Clearly defined roles could also prevent misperceptions of position and power amongst alliance members.

\section{Empathy}

Empathy is the capacity of an entrepreneur to understand subtle and complex social dynamics. Empathy builds cultural acuity, which increases a social entrepreneur's aptitude for building relationships and understanding the needs and values of stakeholders. ${ }^{35,36}$ How can learning social and cultural intricacies lead to micro-conflict resolution? Culture is often described as a personality and character of a social, religious, ethnic, racial, or national group. ${ }^{37}$ In other words, it is a bounded world of beliefs and practices belonging to some type of society. ${ }^{38}$ Ann Swindler describes culture as an "action tool kit", which is a suitable way of interpreting the usefulness of empathy for the purpose of grassroots diplomacy. The greater the capacity to learn and understand what motivates different alliances and how stakeholders make decisions, the more information an entrepreneur has access to while making decisions in lieu of micro-conflicts he or she faces. This information might include relevant social, economic, and technical aspects of the venture in addition to political, legal, cultural, and environmental factors that influence the entrepreneurial ecosystem. Swindler suggests that an individual's process of making decisions reflects a pre-constructed set of norms and principles, determining how information is valued. ${ }^{39}$ In her eyes, culture guides decision-making. Social entrepreneurs gain insights into their own and others' cultures through reflective exercises and strategic observation. The information encourages entrepreneurs to consider their own style of action and how it differs from the actions of their partners and stakeholders. Empathic entrepreneurs can understand how to build harmony among the alliances they form and maintain strong social ties between others.

As empathizers build consciousness by stepping in the shoes of a community alliance or stakeholder, they become aware of the diverse cultural characteristics, values, symbols, norms, and customs of those within the community in which they engage. A willingness to engage with members of the community through language learning, shared cultural experiences, and storytelling creates a series of positive effects. A background of the cultural elements of conflict resolution styles also helps social entrepreneurs to be more aware of the impact of their actions and facilitates a more impactful ecosystem. For instance, certain cultures are considered either individualistic or communitarian. The individualist makes decisions based on personal values and uses direct confrontation and communication styles. Communitarians tend to use less confrontational means for resolving conflict and often their behavioral motivations reflect a desire to maintain group harmony and hierarchal decision-making institutions. ${ }^{40,41}$ They enter 
conflicts less often because of personal motivations and more often when cultural norms are violated. $^{42}$ Empathy leads to greater contextual awareness and can help ventures avoid or adequately negotiate challenging situations like those associated with motivations, expectations, position, and power.

\section{Trust-based Relationship Building}

The concept of trust-based relationship building has two tangible components: the duration of a relationship and an insistence on ethical decision-making. As the quintessential value of collaborative relationships, trust is a value that social entrepreneurs must build. Trust raises the value of an enterprise through the activation of individuals, networks, and communities. ${ }^{43}$ How does one build trust effectively? Over time, openness and empathy demonstrate that entrepreneurs not only seek to operate efficiently with others, but also facilitate trust growth processes. For example, through role-modeling and explicit encouragement, entrepreneurs can increase agency and foster a culture of mutual benefit and reciprocity. ${ }^{44}$ As the venture meets its social and economic expectations and shares ownership in key decision-making processes, trust will deepen among individuals.

Acting ethically at all times and avoiding decisions that lead to distrust and suspicion is another factor that leads to trust-based relationship building. The availability of partnerships among diverse stakeholders could lead individuals to seek opportunities for self-advancement through personal and professional achievement, especially when the stakeholder elevates his or her own stakes through active participation. ${ }^{45}$ Such perspectives threaten the entrepreneurial ecosystem whenever an opportunity for personal or professional advancement impedes the progress of the venture. "Cultural values", such as norms and perceptions related to trustbuilding, also differ for different cultures, and expose a view of trust that can be difficult to maneuver. ${ }^{46}$ For instance, throughout the world, people offer grease payments or bribes to influence a decision between negotiating individuals. ${ }^{47}$ The translation of this challenge for the entrepreneur becomes obvious when considering the implication of such payments that can be seen as normal behavior in certain cultural settings. By receiving the payment or offering financial incentives, entrepreneurs concede to what they perceive is unethical behavior and build a relationship founded on an unethical practice. By not accepting the bribe, the entrepreneur may inhibit the progress of a certain negotiation or thwart the growth of a strategic partnership.

\section{Equitable Collaboration}

Equitable collaboration means fairness in the amount of time, money and energy expended by one partner for the benefit they incur. Equitable collaboration has been shown to foster increased coordination, communication, open-mindedness, critical thinking, leadership development, understanding of sources of conflict, and development of skills for negotiating micro-conflict resolution. $^{48,49}$ For instance, local knowledge often contributes to technical solutions of unpredicted problems because indigenous members of the community have more knowledge about local markets and how to manage resources within the community. ${ }^{50}$ On the other hand, investors and innovators who have more physical resources to contribute will seek solutions that will be sufficiently advantageous economically. Social entrepreneurs need to be sensible in their balancing act of inspiring action and a sense of ownership for those who have indigenous skills and knowledge systems while also feeling there is equity in physical assets and resources used. One method to ensure equitable collaboration is to measure the extent to which money, time, and energy are balanced among stakeholders. ${ }^{51}$ 
Equity in the decision-making process also builds mutually beneficial and reciprocal relationships and mobilizes relevant alliances, whether a customer, partner, community member, government institution, or non-governmental organization, to envision their own short-term and long-term objectives. ${ }^{52}$ One actionable strategy for practicing equitable decision-making is through consensus building, a form of collaboration that requires the active participation in decision-making and approval of solutions by all parties. ${ }^{53}$ Since all relevant stakeholders are involved in decision-making, the final decision reflects the values, needs, and perspectives of each participant and is more likely to produce favorable outcomes. Consensus building is a multi-step process. First, the actors or participants convene and set an agenda to define the problem. Then, the actors brainstorm alternative options with the freedom to express their own needs, ideas, and concerns. ${ }^{54}$ Successful resolutions occur when both parties perceive that shortterm and long-term benefits of a course of action exceed the costs. ${ }^{55}$ This decision-making structure, if facilitated adequately, inherently provides a "win-win" situation for everyone. ${ }^{56}$

\section{Conflict Resolution}

Conflict resolution for grassroots diplomacy refers to the tactical responses an entrepreneur needs to use if tensions or disagreements escalate and compromise the wellness of the entrepreneurial ecosystem. Overcoming interpersonal conflicts is important, so learning conflict resolution skills is essential. ${ }^{19}$ It encapsulates an approach to viewing conflicts and resolving them in a manner that strengthens the relationships affected by the consequences of a microconflict. $^{8}$ Gandhi utilized an empathetic understanding of people, their problems, and their motivations. Each conflict existed as a function of the individual's ego, expectations, and motivations. Therefore, conflict resolution was an opportunity to transform the self and others and was a response focused on the nature of a problem and not just its consequences. ${ }^{57}$ The ability to define the nature of each problem as unique based on the stakeholders involved and their diverse worldviews will enhance micro-conflict resolutions.

So, what does Gandhigiri look like in its practical application during engagement? Acting against individual self-interest, to an appropriate extent, helps entrepreneurs focus on building relationships, and ultimately, to resolve conflicts in a manner that benefits the entrepreneurial ecosystem as a whole. ${ }^{58}$ To do so, entrepreneurs need to resist unethical or uncivil behavior and bullying. For example, in response to bribery requests, entrepreneurs need to elicit a response that will transform the mindset of the one who offered the bribe. When individuals in India responded to bribery requests by paying with a note for the amount of zero rupees, they resisted the unethical behavior in a creative way: instead of directly addressing the bribe, they enabled a greater sense of understanding for the unethical nature of bribery. ${ }^{59}$

Grassroots diplomacy therefore focuses on change through empathetic transformation, not through embarrassment or humiliation. ${ }^{60,61}$ Through a Gandhian approach, the output resulting from conflict becomes one of respect instead of hatred, especially if the entrepreneur is successful in "saving face", or preventing individual actors from feeling ashamed. Visionary leaders acknowledge the importance of saving face for the success of diplomacy, referring to a strategic approach that builds for opponents "a golden bridge to retreat across". ${ }^{2}$ People wish to be honored and maintain dignity while avoiding dishonor and humiliation. An act that saves face will overcome the feeling of shame and disgrace that arises when a partner or key stakeholder makes a mistake, confronts a situation that challenges honor, or feels humiliated.

Social entrepreneurs become ambassadors of their individual nationalities, disciplines, and cultures when they travel to foreign places. As ambassadors, there is a need to work 
harmoniously with all stakeholders. Understanding the intricacies of cross-cultural communication reveals the existence of subtle power dynamics and facilitates relationship building. Face-giving actions can also be utilized reactively by conveying the admission of error and mistake in a positive light, enhancing the honor of the other actor. Communication barriers lead individuals to feel embarrassed by their lack of language proficiency. Learning the native languages, or even attempting the language despite probable pronunciation failure, can help alleviate tensions with others. An expertise in the delicate forms of face-saving helps entrepreneurs navigate in various circumstances. It is especially effective when discord among group members affects how individuals engage in dialogue and collaborate on the design or implementation of business plans. The actions of Gandhigiri, face-saving and face-giving, are examples of strategic tactics that entrepreneurs should utilize when escalated tension and disagreement threatens the entrepreneurial ecosystem's structure and wellness.

\section{Ethical Reflection}

Ethical decision-making is crucial for grassroots diplomacy and reflection is an exercise that enlightens entrepreneurs of the true consequences of their decisions and helps them understand the growth of the previous five competencies. Proactive scenario planning teaches that people have the ability to predict future possible events and learn about the motivations, expectations, and perceptions of others. ${ }^{63}$ Ethical reflection accomplishes the same feat by observing and learning from decisions made and actions taken in the past. Teaching aspiring social entrepreneurs to independently make ethical decisions requires reflection and a careful understanding of how they ought to act. Social entrepreneurs already have a predisposition for improving the status quo for communities in the developing world. However, training and instructing on ethical decision-making is a delicate process that can be most effectively practiced in the following three methods: "1) First, intellectual instruction that focuses on teaching [...] the foundations of morals, the pertinent definitions, and how to apply ethics to real-world situations. 2) The study of particular knowledge nuances the field of ethics by covering ethical codes, universal ethical issues, and how ethical issues can evolve and transform within varying contexts. 3) Engaging [...learners] emotionally, fostering within them a caring tendency, and subsequently assessing levels of affection." ${ }^{64}$ It is important that practitioners of grassroots diplomacy, when working in new and foreign contexts, know how to conduct themselves ethically and make appropriate decisions. ${ }^{65}$

Structured reflection activities yield more quality insights and hence such activities must be designed with a clear idea of the goal and how the reflection activity contributes to progress towards learning and practicing grassroots diplomacy. Case study analysis provides a structured mechanism through which individuals can view ethical problems. When presented with real problems, entrepreneurs employ analytical processes and work to reach consensus with their colleagues in determining the best course of action. The problems are complex in nature, making straightforward solutions difficult to come by. The discussions that occur during case study analysis evoke memories of situational decisions made during international experiences. Social entrepreneurs internalize the notion that international development should provide individuals the ability to self-determine their futures, unrestricted by a lack of resources. It is of paramount importance that practitioners, who lack experience working in certain regions of the developing countries, engage in discourse regarding the nature of their international work to ensure their actions reflect their intentions and they uphold the fundamental tenet of self-determination. 


\section{GRASSROOTS DIPLOMACY METHODOLOGY}

The Grassroots Diplomacy Methodology is a tool to identify micro-conflicts and handle problematic situations systematically in the best interest of all key stakeholders. Social entrepreneurs bring to bear their conflict-resolution competencies and a mindset that respects reciprocity and self-determination to overcome challenging situations by identifying one appropriate course of action. The Grassroots Diplomacy Methodology enables entrepreneurs to focus their efforts and ensure that they consider all the relevant intricacies. It also builds confidence in decision-making and a solutions-orientation, as it requires the careful examination of various possible courses of action and the implementation of an effective solution. Ethical dilemmas and conflicts experienced when working closely with diverse entities are often sensitive and multi-faceted. They are infused with norms and principles held by individuals with diverse personal upbringings and past experiences. Finding a course of action is not always straightforward, yet every decision an entrepreneur makes can impact the success of their relationships and their ventures. The method shown in Figure 3 is a 7-step approach to individual cases that has been adapted from the National Institute for Engineering Ethics. ${ }^{66}$

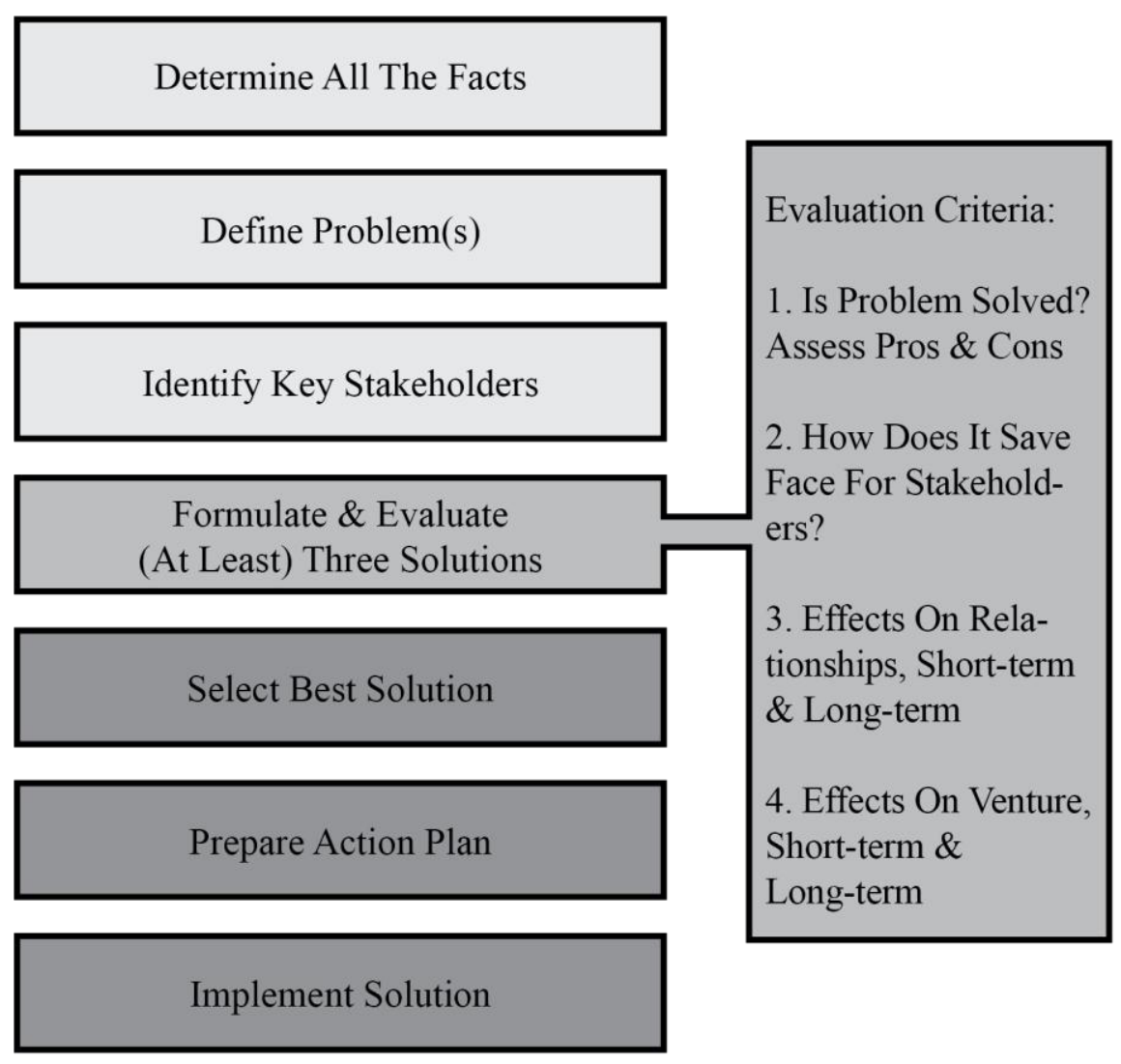

FIGURE 3

THE GRASSROOTS DIPLOMACY METHODOLOGY 
Using this method, entrepreneurs reflect on the holistic nature of their decisions and implement effective solutions. They define the problem as consisting of one or more micro-conflicts by collecting all of the unbiased information available. Entrepreneurs then acknowledge the extent to which stakeholders have a vested interest in the outcome of the problem's solution. Once the information is collected and stakeholders identified, entrepreneurs determine several possible courses of action that could effectively solve the problem. It is a tremendous challenge to take an action and attempt to fully comprehend the ethical and interpersonal implications of the decision. Therefore, each solution developed through moral imagination must be evaluated by the following criteria: 1.) Evaluating the pros and cons of each solution and how it addresses the problem. 2.) Assessing the extent to which each solution successfully saves face for stakeholders. 3.) Assessing the solution's impact on stakeholder relationships in the short-term and long-term. 4.) Assessing the solution's impact on the venture in the short-term and long-term. By following these steps, various solutions will appear more effective in addressing the problem, building relationships, and advancing the venture. Once all possible choices are sufficiently evaluated, entrepreneurs will select, prepare, and implement the best solution. It must be noted that the specific steps taken to resolve the issue merit careful analysis as well.

Many of the core competences described earlier come into play throughout this process. In discovering the nature of problems and identifying key stakeholders, entrepreneurs practice scenario-planning and empathy. Focused at all times on advancing the venture, entrepreneurs develop awareness of the growth of their partnerships and the achievement of their own personal and professional motivations. They proceed in a manner that generates trusting relationships, equitable collaboration, and lasting resolutions to conflicts. Finally, reflective activities clarify a course of action and measure its effectiveness within the context of the entrepreneurial ecosystem. Social entrepreneurs need to learn the implications of their approach to a specific problem in relation to key stakeholders and partnerships. By focusing reflective activities towards the acquisition of the grassroots diplomacy competences, entrepreneurs enhance the process of micro-conflict resolution in the short-term and develop necessary competences to resolve problems in the future.

\section{CONCLUSION}

Building strong alliances is essential to developing and maintaining an effective and sustainable entrepreneurial ecosystem. Community partnerships and global networks expand the potential of social enterprises when they are empowered by healthy working relationships. By engaging directly and collaborating effectively, entrepreneurs develop systems with agents seeking their own means for personal and professional development. However, various kinds of microconflicts inhibit the processes of engagement and collaboration. These obstacles emerge due to different cultural perceptions as well as common problems like handling tension in high-pressure environments. Grassroots diplomacy is the process of micro-conflict resolution that social entrepreneurs utilize to navigate the complex dynamics of their working relationships.

Self-determination and a systems thinking approach foster a better understanding of the true nature of working relationships in the context of developing social ventures and serve as the foundation for grassroots diplomacy. When independent individuals make decisions, they act autonomously based on their beliefs, values, and internalized norms. Systems thinking approaches demonstrate that the venture as a whole and all of its component parts are interdependent. This includes individual actors, or alliances, which assist entrepreneurs in 
achieving their objectives. Through self-determination, entrepreneurial alliances also become the agents of their own development, and the entire entrepreneurial ecosystem achieves its objectives of addressing global development challenges with more success.

Grassroots diplomacy is not merely a method for resolving conflicts, but also for resolving them in a way that enables long-term alliance-building. Further, social entrepreneurs who practice the core competences of grassroots diplomacy retain a series of skillsets that will be useful to ensure that the design and implementation of their social enterprise operates harmoniously. Without understanding these concepts and dynamics, entrepreneurs run the risk of building tensions among stakeholders or failing to instill a sense of self-determination entirely. Therefore, the core competences and grassroots diplomacy methodology need to be utilized by social entrepreneurship educators, students, and practitioners. As a recommendation to interested scholars, effectively designed measurement tools for one or more of the core competences will increase the efficacy for learning the skillsets defined and described in this article. By crafting a series of academic or professional training curricula using the core competences as learning objectives, educators can prepare aspiring social entrepreneurs to build stronger ventures and sustainable entrepreneurial ecosystems. 


\section{REFERENCES}

${ }^{1}$ Lucena, J \& Schneider, J 2007, 'Engineers, development, and engineering education: From national to sustainable community development', European Journal of Engineering Education, pp. 247-257.

2 Dym, C, Agogino, A, Eris, O, Frey, D \& Leifer, L 2005, 'Engineering Design Thinking, Teaching, and Learning', Journal of Engineering Education, pp. 103-120.

${ }^{3}$ Tsang, E, van Haneghan, J, Johnson, B, Newman, EJ \& van Eck, S 2001, 'A Report on Servicelearning and Engineering Design: Service-Learning's Effect on Students Learning Engineering Design in 'Introduction to Mehchanical Engineering", International Journal of Engineering Education, vol 17, no. 1, pp. 30-39.

${ }^{4}$ Ropers-Huilman, B, Carwile, L \& Lima, M 2005, 'Service-learning in engineering: a valuable pedagogy for meeting learning objectives', European Journal of Engineering Education, vol 30, no. 2, pp. 155-165.

${ }^{5}$ Maley, S, Perez, A, \& Mehta, K, “The Significance of Implementation Strategy for Scaling-Up Base of Pyramid Ventures," NCIIA Annual Conference, Washington DC, March 2013

${ }^{6}$ Fiksel, Joseph. "Designing Resilient, Sustainable Systems." Environmental Science and Technology (Eco-Nomics LLC) 37, no. 23 (2003): 5330-5339.

${ }^{7}$ Leydens, JA \& Lucena, C 2006, 'The Problem of Knowledge in Incorporating Humanitarian Ethics in Engineering Education: Barriers and Opportunities', Frontiers in Education Annual Conference, ASEE/IEEE, San Diego.

${ }^{8}$ Mehta, K., Dzombak, R., "Ethical Decision-Making and Grassroots Diplomacy for Social Entrepreneurs: Concepts, Methodologies and Cases," International Journal of Social Entrepreneurship and Innovation, Vol. 2, No. 3, pp. 203 - 224, 2013

${ }^{9}$ Vogel, P. (2013). 'The Employment Outlook for Youth: Building Entrepreneurial Ecosystems as a Way Forward', College of Management of Technology, G20 Youth Forum, 2013.

${ }^{10}$ Smith, W, Besharov, M, Wessels, M \& Chertok, M 2012, 'A Paradoxixal Leadership Model for Social Entrepreneurs: Challenges, Leadership Skills, and Pedagogical Tools for Managing Social and Commercial Demands', Academy of Management Learning \& Education, pp. 463478.

${ }^{11}$ Alkire, S. (2005). Subjective quantitative studies of human agency. Social Indicators Research, 74, 217-260.

12 Sen, A. (1999). Development as Freedom. New York, NY: Anchor Books.

${ }^{13}$ Ryan, R. M., \& Deci, E. L. (2000). Self-Determination Theory and the Facilitation of Instrinsic Motivation, Social Development and Well-being. American Psychologist, 55(1), 6878.

${ }^{14}$ Lisman, C. David. The Curricular Integration of Ethics: Theory and Practice. London: Praeger Publishers, 1996.

${ }^{15}$ Ibrahim, Solava, and Sabina Alkire. Agency and Empowerment: A Proposal for Internationally Comparable Indicator. Oxford Poverty and Human Development Initiative, 2007.

${ }^{16}$ Prahalad, C.K. and Hart, S.L. (2002) 'The fortune at the bottom of the pyramid', Strategy+Busines2s 6(First Quarter):2 - 14.

${ }^{17}$ Pless, Nicola. "Social Entrepreneurship in Theory and Practice." Journal of Business Ethics (2012) 111, no. 3 (2012). 
${ }^{18}$ Mehta, Chanakya, Rachel Dzombak, Khanjan Mehta, and Sven G. Bilén. "The Relevance of Systems Thinking Tenets in the Quest for Multifinal Social Enterprises." Systemic Practice and Action Research, 2013.

${ }^{19}$ Miller, Toyah L, Curtis L Wesley, and Denise E and Williams. "Educating the Minds of Caring Hearts: Comparing the Views of Practitioners and Educators on the Importance of Social Entrepreneurship Competencies." Academy of Management Learning and Education 11, no. 3 (2012): 349-370.

${ }^{20}$ Longnecker, Justin G., McKinney, Joseph A., Moore, Carlos W. "Egoism and Independence: Entrerpreneurial Ethics." Organizational Dynamics, 1975: 64-72.

${ }^{21}$ Schmitz, Hubert. "Growth Constraints on Small-scale Manufacturers in Developing Countries: A Critical Review." World Development (Pergoman Press Ltd.) 10, no. 6 (1982): 429-450.

${ }^{22}$ Simon, Stephen. The seven deadly sins of social enterprise. Liam Black. December 13, 2012. http://socialenterprise.guardian.co.uk/social-enterprise-network/2012/dec/13/seven-deadlysins-social-enterprise (accessed June 6, 2013).

${ }^{23}$ Mair, Johanna, Marti, Ignasi, Ventresca, Marc J. "Building Inclusive Markets in Rural Bangladesh: How Intermediaries Work Institutional Voids." Academy of Management Journal, 2012: 819-850.

${ }^{24}$ Barker, Michelle, Elisha Frederiks, and Brona Farrelly. "Managing Cross-Cultural Conflict Productively." GIHE Good Practice Resource Booklet on Designing Culturally Inclusive Learning and Teaching Environments. 15 12, 2009.

${ }^{25}$ Villenas, Sofia. "The Colonizer/Colonized Chican Ethnographer: Identity, Marginalization, and Co-optation in the Field." Harvard Educational Review (President and Fellows of Harvard College) 66, no. 4 (1996): 711-731.

${ }^{26}$ Merriam, Sharan B, Juanita Johnson, Ming-Yeh Lee, Youngwha, Ntseane Kee, and Muhamad Mazanah Gabo. "Power and positionality: negotiating insider/outsider status within and across cultures." International Journal of Lifelong Education 20, no. 5 (2001): 405-416.

${ }^{27}$ Milburn, Norweeta, Lawrence Gary, Jacqueline Booth, and Diane Brown. "Conducting Epidemiologic Research in a Minority Community: Methodological Consideration." Journal of Community Psychology (Howard University) 19, no. 1 (2006): 3-12.

${ }^{28}$ Hovatter, Doug. "Understanding Conflict and Disagreement." West Virginia University Extension Service, 1997.

${ }^{29}$ McGaghie, William C. "Professional Competence Evaluation." Educational Researcher 20, no. 1 (February 1991): 3-9.

${ }^{30}$ Dewey, John. How We Think. New York: D.C. Health and Co., 1910.

${ }^{31}$ Schoemaker, Paul J. H. "Multiple Scenario Development: Its Conceptual and Behavioral Foundation." Strategic Management Journal (John Wiley \&) 14 (1993): 193-213.

${ }^{32}$ Miesing, Paul, and Ray Van Ness. "Exercise: Scenario Planning." Organization and Management Journal (Eastern Academy of Management Meetings), 2006: 1-11.

${ }^{33}$ Chermack, Thomas J., Susan A. Lynham, and Wendy E.A. Ruona. "A Review of Scenario Planning Literature." Futures Research Quarterly (Future Res), Summer 2001: 7-31.

${ }^{34}$ Burt, George, George Wright, Ron Bradfield, George Cairns, and Kees Van Der Heijden. "The Role of Scenario Planning in Exploring the Environment in View of the Limitations of PEST and Its Derivatives." International Studies of Management and Organization (M.E. Sharpe, Inc.) 36 , no. 3 (2006): 50-76. 
${ }^{35}$ Hofstede, Geert. "Diplomats as Cultural Bridge Builders." Second International Conference on Intercultural Communication and Diplomacy: Organisational and Professional Cultures and Diplomacy. Malta, 2004.

${ }^{36}$ Hughes, Thomas P. Hughes and Agatha C. Systems, Experts, and Computers. US: Massachusetts Institute of Technology, 2000.

${ }^{37}$ Abrams, Zsuzsanna I. "Surfing to Cross-Cultural Awareness: Using Internet-Mediated Projects to Explore Cultural Stereotypes." Foreign Language Annals 35, no. 2 (April 2002): 141-160.

${ }^{38}$ Sewell, William H. "Concept(s) of Culture." In Beyond the Cultural Turn, edited by Victoria E. Bonnell and Lynn Hunt, 35-61. London: University of California Press, Ltd., 1999.

${ }^{39}$ Swidler, Ann. "Culture in Action: Symbols and Strategies." American Sociological Review (American Sociological Association) 51, no. 2 (April 1986): 273-286.

${ }^{40}$ Rosenberg, Sarah. Face. February 2004. http://www.beyondintractability.org/bi-essay/face (accessed 2013).

${ }^{41}$ LeBaron, Michelle. Communicatin Tools for Understanding Cultural Differences. June 2003. http://www.beyondintractability.org/bi-essay/communication-tools.

${ }^{42}$ Chen, Guo-Ming, and William J. Starosta. "Chinese Conflict Management and Resolution: Overview and Implications." Intercultural Communication Studies 7, no. 1 (1998): 1-16.

${ }^{43}$ Curtis, Timothy, Jan Herbst, and Marta Gumkovska. "The social economy of trust: social entrepreneurship experiences in Poland." Social Enterprise Journal 6, no. 3 (2010): 194-209.

${ }^{44}$ Smith, Wendy K. Marya L. Besharov, Anke K. Wessels, and Michael Chertok. "A Paradoxical Leadership Model for Social Entrepreneurs: Challenges, Leadership Skills, and Pedagogical Tools for Managing Social and Commercial Demands." Academy of Management Learning \& Education 11, no. 3 (September 2012): 463-478.

${ }^{45}$ Sarasvathy, Saras and Dew, Nicholas. "Effectuation and Over-Trust: Debating Goal and Karri." Entrepreneurship Theory and Practice (Baylor University) 32, no. 4 (2008): 727-737.

${ }^{46}$ Husted, Bryan W. "Wealth, Culture, and Corruption." Journal of International Business Studies (Palgrave Macmillan Journals), 1999.

${ }^{47}$ Cairns, Jo, Dennis Lawton, and Roy Gardner. Values, Culture and Education. New York: Routledge Taylor \& Francis Group, 2001.

${ }^{48}$ Groeneboer, Chris, Denise Stockley, and Tom Calvert. "A Model for Multi-Disciplinary Collaboration." Burnaby, BC, 1997.

${ }^{49}$ Dickinson, Terry L., and Robert M. McIntyre. "A Conceptual Framework for Teamwork Measurement." Team Performance Assessment and Measurement, 1997: 19-43.

${ }^{50}$ Warren, Dennis M. Using indigenous knowledge in agricultural development. Vol. 127. Washington, DC: The World Bank, 1991.

${ }^{51}$ Mehta, Chanakya, and Khanjan Mehta. "A Design-Space and Business-Strategy Exploration Tool for Infrastructure-based Ventures in Developing Communities." International Journal for Service Learning in Engineering 6, no. 2 (2011): 30-57.

${ }^{52}$ Mehta, K., Brannon, M., Zappe, S., Colledge, T., Zhao, Y., "eplum Model of Student Engagement: Expanding non-travel based Global Awareness, Multi-disciplinary Teamwork and Entrepreneurial Mindset Development", International Division, ASEE Annual Conference, Louisville, Kentucky, June 2010

${ }^{53}$ Conflict Research Consortium. Consensus Building. Conflict Research Consortium. 1998. http://www.colorado.edu/conflict/peace/treatment/consens.htm (accessed June 20, 2013).

${ }^{54}$ SeedsforChange. Consensus Decision Making. 2013. http://seedsforchange.org.uk/consensus (accessed June 20, 2013). 
${ }^{55}$ Zartman, I. William. "The Timing of Peace Initiatives: Hurting Stalemates and Ripe Moments." The Global Review of Ethnopolitics (Johns Hopkins University) 1 (October 2001): 8-18.

${ }^{56}$ Lehrer, Keith. "Individualism, Communitarianism, and Consensus." The Journal of Ethics (Springer) 5, no. 2 (2001): 105-120.

${ }^{57}$ Nakhre, Amrut. "Meanings of Nonviolence: A Study of Satyagrahi Attitudes." Journal of Peace Research (Sage Publications, Ltd.) 13, no. 3 (1976): 185-196.

${ }^{58}$ Weber, Thomas. "Gandhian Philosophy, Conflict Resolution Theory and Practical Approaches to Negotiation." Journal of Peace Research (Sage Publications, Ltd.) 38, no. 4 (July 2001): 493-513.

${ }^{59}$ Ruskin, Jay. Sometimes Corruption can be Subtracted by Dividing a Bureaucrat by Zero. 02 12, 2010. http://www.ufppc.org/us-a-world-news-mainmenu-35/9407-news-sometimescorrpution-can-be-subtracted-by-dividing-a-bureaucrat-by-zero.html (accessed 06 09, 2013).

${ }^{60}$ Power, Paul F. The Meanings of Gandhi. University Press of Hawaii, 1971.

${ }^{61}$ Kuula, Markku, and Antonie Stam. "A win-win method for multi-party negotiation support." International Transactions in Operational Research 15 (2008): 717-737.

62 Thrush, Glenn. President Obama's State of the Union: Aggressive. February 11, 2013. http://www.politico.com/story/2013/02/state-of-the-union-2013-obama-aggressive87440.html (accessed April 12, 2013).

${ }^{63}$ Schwartz, Peter. The Art of the Long View. New York, New York: Doubleday, 1991.

${ }^{64}$ Newberry, B 2004, 'The Dilemma of Ethics in Engineering Education', Science and Engineering Ethics, pp. 343-351.

${ }^{65}$ Wilhelm, PG 2002, 'International Validation of the Corruption Perceptions Index: Implications for Business Ethics and Entrepreneurship Education', Journal of Business Ethics, pp. 177-189.

66 '9 Basic Steps to Personal Ethical Decision-Making,' Texas Tech University Murdough Center for Engineering Professionalism http://www.depts.ttu.edu/murdough center/products/resources/steps-to-personal-ethical-decision-making.php 